Disease in Children, this is the first instance of cirrhosis of the suprarenal capsules that bas been recorded. The importance of not passing the kidneys as healthy on the evidence of a macroscopical examination alone is once more exemplified.

Welbeck-street, W.

\section{THE DIAGNOSIS AND LOCALISATION OF TUMOURS OF THE FRONTAL REGIONS} OF THE BRAIN. ${ }^{1}$

\section{By T. GRAINGER STEWART, M.B. EdIN.,} M.R.C.P. LOND.,

ASSISTANT PHYSICTAN TO THE METROPOLITAN HOSPITAL, RINGSLANDROAD, LONDON, N.E. ; PATHOLOGIST'" THE NATIONAL HOSPITAL FOR THE PARALYSED ANI QUEEN-SQUARE, W.C.

THE clinical picture of frontal tumour is characterised by the absence of signs pointing to involvement of other regions of the brain rather than by the presence of special focal symptoms. In many cases in which the cardinal symptoms of intracranial growth, headache, vomiting, and optic neuritis, are alone present the diagnosis can be arrived at only by a process of exclusion, and then the question as to whether the lesion is right- or left-sided has still to be answered. There are, however, many points which help in deciding this question, and although their individual importance may appear slight yet when they are considered collectively they combine to form a distinct and definite clinical entity. ${ }^{2}$

Before discussing the symptoms and signs of frontal tumours with reference to their localising value it is well to define what is meant by the term "frontal region" and to review shortly our knowledge of the functions of this portion of the brain.

Under the term "frontal region" only that part of the brain is included which lies anterior to the ascending frontal convolutions. The results of experimental research $(1,5,6,8,9)$ and clinical and pathological investigation have divided this area on physiological grounds into two distinct parts. Electrical stimulation of the anterior two-thirds, which is known as the prefrontal region, has yielded negative results as far as motor signs are concerned, but its destruction has brought about ill-defined mental changes. In the posterior third, or post-frontal region, stimulation experiments have demon. strated the presence of centres for the turning of the head and eyes to the opposite side and also for some other ocular movements (17), and destruction of this region has produced paralysis of these movements and deviation of the head and eyes to the side of the lesion. These higher oculo-motor centres are situated in the hinder parts of the first and second frontal convolutions. Further, in the posterior end of the third frontal convolution of the left side lies the specialised motor centre for speech in the area included between the anterior and ascending limbs of the fissure of Sylvius, known as Broca's convolution. The other motor centres are placed behind the frontal region in the ascending frontal gyrus and are arranged from above downwards in the following order: leg, trunk, arm, hand, face, and mouth; the centres for the face and mouth being opposite the posterior end of the third frontal convolution.

Notice must be taken of A. W. Oampbell's (4) subdivision of the frontal lobes on the basis of their histological architecture. Campbell calls the motor area the precentral area, and the rest of the ascending frontal gyrus and the hinder ends of the three frontal convolutions is his "intermediate precentral area," which thus corresponds to what I have named the post-frontal region. The rest of the frontal lobe, which is here termed the prefrontal area, is divided by Campbell into a larger posterior portion or frontal area and a smaller anterior part, which is all he includes under the

1 The figures in parentheses occurring throughout the article have reference to the bibliography at the end.

The clinical factors which are set forth in this paper are based upon the study of 22 cases of tumour of the frontal region which I have had the opportunity of observing in the National IIospital for the Paralysed and Epileptic during the past four years. In all these cases the diagnosis was confirmed either by necropsy or operation. I have to express my thanks to the medical staff of the hospital for their courtesy in permitting me to make use of their cases. term "prefrontal." Bolton (2), in his important paper on the frontal lobes, comes to the conclusion that the region which is here connoted by the term prefrontal, and which corresponds to Flechsig's anterior association centre, is the portion of the brain which is concerned with the performance of the highest coördinating and associational processes of the mind, that it is undeveloped in all grades of primary mental deficiency, and that its atrophy is the anatomical basis of dementia.

The general symptoms of intracranial neoplasm-headache, vomiting, and optic neuritis-are usually present in cases of frontal tumour, but their development may be gradual when the illness, as is often the case, is of long duration. The headache and the optic neuritis are important in view of localisation. The beadache is as a rule frontal in situation but not infrequently occipital. If it is severe and constant in the frontal region it is often referred to the side of the tumour, especially when the growth is situated on or near the surface of the brain and it is then often accompanied by tenderness on cranial pressure. Optic neuritis frequently develops late in the course of the illness and it is thus possible in many cases to study its onset and its course. R. Marcus Gann (7) from a study of the statistics of optic neuritis in cerebral tumour compiled by J. M. Martin has called attention to the fact that unilateral neuritis or excess of neuritis on the one side occurs most frequently in cases of frontal tumour and that in the great majority of such cases it is more intense on the side of the lesion. Ed. Müller (14) in an analysis of 168 cases of frontal tumour found that optic neuritis occurred in 80 per cent. and that in four of the five cases in which it was unilateral it was on the side of the tumour. Williamson (19) has also referred to the same point. In my own experience the optic neuritis almost invariably appears first in the eye on the side of the growth and is more intense in it than in the opposite eye. This is so constant a feature that in cases in which the neuritis is just commencing it is of real value in localising the disease. In those cases in which the neuritis has been present for a long time the advent of secondary changes greatly diminishes its localising value.

The mental symptoms which occur associated with frontal tumours must be next considered. So much stress has been laid on the occurrence of psychical changes in these cases that it is necessary to examine them closely. In doing so it is essential to determine how far such mental symptoms are directly due to the position of the tumour, and to exclude the effect of concurrent or coincident factors. In this connexion we must bear in mind : (1) the indirect effect of intracranial neoplasms on the mental functions; and (2) that psychopathic changes may develop coincidently, although independently of the growth; thus we must exclude those cases in which there has been any previous psychical change and cases complicated by syphilitic infection or alcoholic abuse. Bruns (3) and Müller (13) have stated that the occurrence of mental symptoms with frontal tumour has been greatly exaggerated owing to insufficient care having been taken in the exclusion of such complications. There remains, however, a large number of cases in which such complications can be excluded and in which the mental symptoms have definitely preceded the onset of the more general and localising symptoms. It is of the greatest importance to find out from those who have previously known the patient intimately, when any change in character or mental state was noticed, for it is obviously impossible to estimate any deterioration of the mental condition or any change in character without some previous knowledge of the life and character of the patient. The onset of the mental change is as a rule gradual and it usually precedes the development of the general symptoms of intracranial tumour. The most prominent and constant changes are inattention and inability to keep the mind fixed on the subject at issue, associated with a tendency to irrelevance and incoherence in conversation. Attention cannot be sustained and seems to lapse, although it may be again easily fixed by an effort on the part of the patient. Lloyd (12) has called attention to cases of frontal tumour in which there was inhibition of thought with an increase in the reaction time of cerebration. In two of my cases this was noticeable, the patients exhibiting a peculiar slowness in answering even the most simple questions, although the answers when given were correct and intelligent.

A loss of memory, more especially for recent events, is often a prominent feature; but perhaps most characteristic of the site of growth are those slight and indefinite mental 
changes and alterations of temperament which are difficult to analyse or describe. The patient is casual and irresponsible in word and deed, and may attempt jokes and make remarks which are quite irrelevant and often rude; this is apparently due to a faulty or too free association of ideas which is not held in check by a rational judgment and a normal power of concentration on the subject; this peculiar state has been observed by Jastrowitz (10), Bruns (3), Oppenheim (15), and has been referred to by Williamson (19) as very characteristic. The association of lassitude and drowsiness with frontal tumour has been emphasised and also the loss of cleanly instincts, patients frequently passing their urine and frees in bed without showing any concern or contrition; but these features, though often met with in cases of frontal tumour, are as commonly present in cases of temporo-sphenoidal and basal growths and therefore cannot be regarded as characteristic either of the site of the tumour or of the mental condition. In cases of long duration the psychical state may deteriorate to dementia or the patient may develop delusions and mania and in all cases any great increase in the intracranial tension gives rise to a stuporose or comatose condition. My personal experience is not sufficient to determine whether mental changes are more pronounced in lesions of the right or left frontal regions, but certainly, as far as tumours are concerned, my series of cases does not support Phelps's (16) opinion that the occurrence of mental symptoms is associated only with left-sided lesions, as in five cases of tumour of the right frontal lobe which were uncomplicated by syphilis or alcohol the mental affection was extremely characteristic. In cases in which both frontal lobes are affected the psychical symptoms are more pronounced. It is evident from a review of my cases that the recovery of mental power after operation is greatest in those cases in which the growth is extra cerebral and the frontal lobes only involved secondarily, as in cases of fibroma or endothelioma while in cases in which the growth involves the brain substance directly as glioma the recovery is never so rapid or so complete.

A second very characteristic feature of frontal tumours is the occurrence of various forms of fits and seizures. Epileptiform seizures may be associated with tumours in any part of the cerebrum but they seem to be especially frequent in frontal tumours. Such attacks were noted in 19 of the 22 cases of this series, and Müller (14) states that out of 168 cases of frontal tumour which he collected more than one-third of the cases had epileptiform seizures either general or focal in character, and they are often the first signs of commencing trouble. These attacks may be classified into four chief varieties: (a) subjective sensations often described as "giddy feelings"; $(b)$ petit-mal attacks ; $(c)$ generalised epileptic seizures; and $(d)$ fits commencing with a localised convulsion. The feelings of faintness or giddy attacks are not accompanied by loss of consciousness. There are simply a sudden feeling of weakness and a tendency to fall. The patients' description is often that they felt faint or giddy, that they had a swimming in the head. These attacks are not associated with auditory phenomena, an important point in distinguishing them from the giddiness associated with aural vertigo and tumours of the eighth nerve. The second class is distinguished from the first by a transitory loss of consciousness. They are identical with the petit-mal attacks of idiopathic minor epilepsy. The third class consists of generalised convulsive seizures, commencing with loss of consciousness and tonic spasm, and passing into clonic spasm, similar to major idiopathic epilepsy. The fourth variety of seizure includes all the attacks with focal origin. These may be slight and limited without loss of consciousness, or the fit may spread and the attack become unilateral or general in distribution. These fits are of special interest; the presence of motor centres in the postfrontal region and the contiguity of the motor area to the frontal region account for their frequency and character. They may be divided into two chief types: $(a)$ those which commence with a discharge from the centres in the postfrontal region and $(b)$ those which originate from excitation of the motor centres of the precentral gyrus.

In the first type the fit commences with turning or jerking of the head and eyes to the opposite side and these may be the only movements which occur, consciousness being preserved. In such slight attacks the patients may complain of a feeling of rotation towards the side of the lesion presumably due to the apparent displacement of the envirorment consequent on the rapid involuntary movement of the eyes. Such a fit may spread to the face and mouth, arm, leg, and trunk, or it may become more severe and generalised with loss of consciousness. It is of importance to note that these attacks are never ushered in by sensory auræ. In addition to the character of the fits, which are frequently unobserved or incompletely described, the phenomena of the post-convulsive stage may be of great importance in the localisation of the disease. After severe seizures the head and eyes are in paralytic deviation to the side of the lesion and there may be temporary hemiparesis of the contralateral side, but the recovery of motor power is rapid. It returns last to those muscles required for the movement of the head and eyes to the opposite side. This is well shown by the weakness of the homolateral sterno-mastoid muscle. Such fits point to the primary irritation and secondary exhaustion of the centres in the post.frontal region. Temporary hemi. anæsthesia of the contralateral side may be present after a severe fit but there is never hemianopia. The loss of sensation passes off quickly, sometimes in the manner of cortical anæsthesia-viz, sensibility returns first to the body and the proximal portions of the limbs, the distal parts of the extremities being the last to recover; but in other cases the return of sensation is more irregular.

The second type of focal fit occurs when the growth is situated in the left frontal region and the patient is right handed. It is characterised by a sudden loss of speech, followed by twitching of the mouth and face on the opposite side (right) and often accompanied by the involuntary emission of indefinite articulated sounds. Consciousness may remain unimpaired and the patient can signal for help, although unable to speak. The discharge may spread to the neighbouring centres and a Jacksonian fit of the ordinary march supervene. I have had the opportunity of observing several such attacks; in some of them there was no move ment of the head and eyes to the opposite side, but as a rule this movement occurs almost simultaneously with the facial spasm. If the fit be severe the power of speech returns slowly but completely. The aphasia, so far as my observation goes, is purely motor in character, the patient being able to understand what is said to him. The association of such attacks with mental symptoms has more than once led to the supposition that the patient was suffering from general paralysis of the insane, but in contrast to that disease the patient recovers with much greater rapidity from the seizures and their after-effects are less severe.

The occurrence of fits with focal beginning reveals plainly the side of the tumour, and the absence of any sensory aura makes any question as to the post-Rolandic situation of the growth untenable. Contrasted with the fits which result from disease of the motor centres or from lesions situated behind them, the seizures associated with frontal tumours are characterised by the constant absence of sensory auræ, although the patient may complain of a sensation of inability to execute a movement or to perform an act. For instance, a patient in an aphasic attack has a feeling of inability to speak or to move his tongue. In tumours situated behind the motor area, on the other hand, the aura is either a positive sensation of movement of a muscle or muscles where no movement is actually taking place, or, as is more common, there may be a feeling of numbness or tingling.

Cranial nerve symptoms.-Symptoms which can be referred to affection of the cranial nerves are absent in a great number of cases of frontal tumour. When present they are due to the implication of the nerves by the growth or the pressure it exerts upon them. They occur therefore on the same side as the tumour and indicate that the growth is situated on or extends towards the hase of the skull. Here a reservation must be made owing to the occurrence of cranial nerve palsies from indirect pressure due to the increased intracranial tension which results from cerebral neoplasm. The function which suffers most frequently from this cause is that of the sixth nerve which leads to convergent strabismus. The other ocular movements which may occasionally be affected by the direct involvement of a basal frontal tumour rarely suffer from these indirect effects.

Olfactory symptoms are very important from the view of localisation and when other causes, such as nasal disease, can be excluded, loss of smell, especially when unilateral, is of great significance. On the other hand, olfactory or gustatory auræ never usher in fits due to discharges from the frontal lobes. As Hughlings Jackson has pointed out, such sensations of smell or taste frequently occur in cases of 
tumour of the temporo.sphenoidal region in the neighbourhood of the uncus, and in lesions of this region there is frequently loss of smell, but, in contrast to that associated with frontal tumours, it is incomplete and bilateral.

The motor system.-Paresis occurs only when the tumour impinges on the motor cortex or its $\epsilon$ fferent fibres and then contralateral hemiparesis of varying degrees may result. The most definite weakness is in many cases of the opposite side of the face which seems to be represented further anteriorly than are the limbs, and as in all cortical lesions the paresis is greater in volitional than in expressional movement. Apart from such signs which are not strictly of frontal origin, there is one to which particular attention must be drawn as it has not been previously described. It is the occurrence of tremor in the limbs of the side homolateral to the tumour. This tremor may be observed in both the upper and lower extremities but is more constant and better marked in the arm than in the leg. In character the tremor is fine, rapid, and vibratory, and it may often be more easily felt than seen. It is absent during muscular rest and can be best demonstrated by making the patient extend both arms horizontally in front of him with the palms directed downwards and the fingers extended. It will then be noticed that the homolateral arm and hand are in a state of constant fine vibratory tremor in contrast to the contralateral arm in which such tremor is absent. The difference between the state of the two hands can be better realised by placing a palm lightly upon the back of each of the patient's hands. This tremor may not be constantly present in any one case, but in all cases of my personal observation when the patient's condition has enabled it to be looked for it has been observed at one time or another. It occurs in cases in which there is no evidence of interference with the motor system, such as contralateral paresis, as well as in cases where such paresis exists. In a few cases such tremor was observed in both hands but it was more regular and constant and of the typical vibratory nature in that homolateral to the lesion. In two cases in which it was bilateral, necropsies later showed that both frontal lobes were involved. It is of interest that in one of these cases in which no other localising signs were present the occasionally more definite tremor on the one or the other side prevented a definite localisation of the side of the lesion being arrived at. I have never met with similar tremor in association with tumours situated in other regions of the brain.

Sensory system.-Affection of sensation never results directly from a frontal lesion and only occurs after severe fits when the discharge has presumably passed across the motor centres to the post-Rolandic gyrus.

Reflexes. - The condition of the reflexes is of great importance. Deep reflexes. - Tumours limited to the pre-frontal region do not as a rule cause any change in the deep reflexes, but when the growth extends further posteriorly and impinges on the motor area the contra-lateral deep reflexes are increased. Bilateral loss of the deep reflexes was observed in some cases but this condition has been described in connexion with cerebral tumours in all situations. The immediate cause of the disappearance of these reflexes is doubtful but it may probably be explained by the degeneration of the posterior spinal root fibres as a result of the increased pressure of the cerebro-spinal fluid. Superficial reflexes. - The state of the superficial abdominal reflexes is of the greatest importance as these may be definitely affected in cases in which hemiparesis or other focal signs are absent. The first demonstrable sign is absence or diminution of the epigastric or abdominal reflexes on the side contralateral to the tumour, or it may be found that on repeated stimulation the contralateral reflexes are more easily exhausted than the homolateral. This alteration of the superficial abdominal and epigastric reflexes is not a specific sign of frontal lesions but merely the result of an affection, however slight, of the pyramidal system. Its value lies in the fact that it is the earliest demonstrable sign of a commencing hemiparesis. In all of my series of cases this diminution or loss of the superficial abdominal or epigastric reflexes on the contralateral side was observed; in three cases the reflexes were also affected on the same side as the tumour, but in these cases there was evidence of a great increase of the intracranial pressure sufficient to affect both cerebral hemispheres. The best method to elicit these reflexes is to stroke the skin with the blunt end of a pin or pen-holder, and it is absolutely essential to do this lightly, as a false reflex, analogous to the tendon reflexes, can be obtained if the oblique abdominal muscles are suddenly stretched by a too forcible stroke. This spurious abdominal reflex produced by a similar reflex mechanism as the knee-jerk is very readily obtained in many spastic conditions in which the true superficial reflex is lost. It is easily demonstrated by indirect percussion of any part of the abdominal muscles in such a way that the tone of the muscle can react to a sudden elongation of the fibres. Apart from nervous disorders I have only seen loss of the abdominal reflex on one side in two cases of appendicitis, a condition which should not be mistaken for cerebral tumour. The diminution or loss of these reflexes which occurs in acute abdominal conditions, such as appendicitis and enteric fever, is, as a rule, bilateral and has been fully described in a paper on this subject by Rolleston. As age advances it becomes more difficult to obtain these reflexes, owing to such causes as obesity and slackening of the abdominal walls. We may conclude that the loss of the superficial abdominal reflexes on one side in any uncomplicated case of cerebral tumour is direct evidence of the tumour being situated in the opposite cerebral hemisphere.

Still more important as positive evidence of affection of the pyramidal system is the presence of an extensor response of the great toe on stimulation of the sole of the footBabinski's sign. It indicates, when spinal disease can be excluded, a lesion in the opposite side of the brain or brainstem. In cases of frontal tumour the contralateral plantar reflex when not extensor may be of an indefinite type as compared with that of the homolateral side; when this is associated with loss or diminution of the corresponding abdominal reflexes its significance is that of a typical extensor response.

It is unnecessary to dwell on the local external signs, though they may be of value, such as localised tenderness on pressure over the skull, protrusion of the eye, or bulging of the cranium.

To summarise, in diagnosing a tumour of the frontal region we bave to rely on (a) the presence of the general symptoms of intracranial growth; $(b)$ the presence of mental symptoms ; and $(c)$ the absence of focal signs pertaining to other regions of the brain. For localisation we must study the nature of any fits which may occur and be guided by the following signs. 1. Those homolateral to the tumour: (a) the earlier development and greater intensity of the optic neuritis; (b) the presence of a fine vibratory tremor in the extended limbs; (c) the presence of focal cranial nerve symptoms; and $(d)$ the presence of local external signs. 2. Those contralateral to the tumour: (a) diminution or loss of the superficial abdominal or epigastric reflexes; (b) the presence of an extensor or indefinite plantar response with increase of the deep reflexes ; and $(c)$ hemiparesis. Though one or more of these signs may be absent it will be found that the majority of cases of tumour of the frontal lobe can be accurately diagnosed and localised, and this is the more important as there is in no other region of the brain, with perhaps the exception of the cerebellum, in which surgical interference can be advised with a greater prospect of success and with so little danger to the subsequent physical and mental condition of the patient.

Bibliography.-1. Bianchi : Brain, 1895. 2. Bolton : Brain, 1903. 3. Bruns: Deutsche Medicinische Wochenschrift, 1892. 4. Campbell The Localisation of Cerebral Function. 5. Ferrier: Functions of the Brain, second edition, 1886. 6. Ferrier and Turner: Philosophical Transactions of the Royal Society, 1898. 7. Marcus Gunn: Brain, 1898. 8. Griubaum and Sherrington: Proceedings of the Royal Society, vol. Ixxi. 9. Horsley and Schäfer Philosophical Transactions of the Royal Society, 1887, 1888, 1890. 10. Jastrowitz: Archiv für Psychiatrie, Bände ii. and iil. 11. Knapp (P. C.): Boston Medical and Surgical Journal, 1906. 12. Lloyd : Journal of Nerrous and Mental Disease, 1892. 13. Mills : Boston Medical and Surgical Journal, 1906. 14. Muller: Deutsche Zeitschrift fuir Nervenheilkunde, Band ii. Hefte 5 and 6. 15. Oppenheim: Archiv fir Psychiatrie, vol. xxi. 16. Phelps: American Journal of the Medical Sciences, 1906. 17. Risien Russell : Journal of Physiology, 1894. 18. Welt: Deutsche Zeitschrift fiir Klinische Medicin, 1888. 19. Williamson (R. T.) : Brain, 1896.

VAGRANCY IN GLOUCESTERSHIRE.-For many years past very carefully compiled statistics relating to vagrancy in the county have been presented to the Gloucestershire standing joint committee. During the six months of the present year ending Sept. 29th, 41,443 vagrants were admitted into the tramp wards attached to the various workhouses in the county, compared with 47,111 last year, a very considerable decrease. About onethird were supplied with a meal of bread at a cost of $£ 46$, or a little less than $1 d$. per person. 


\section{INFANTILE MORTALITY AND GOATS' MILK.}

By WILliam WRIGHT, M.D.Glasg., D.P.H. Cantab., GENIOR ASSISTANT MEDICAL OFFICER OF HEALTH, GLASGOW.

Hitherto the milk supplied to infants who have been unable to obtain their natural supply-that from their mother's breast-has been obtained almost entirely from the cow. To show that the cow is not so well suited for this purpose as the goat is the object of this paper. The objections to the cow's milk as compared with the goat's are so manifold as to merit the immediate attention of all local authorities. This subject has occupied my attention for some months, and it is my desire now to place the information which I have obtained from various quarters before the medical profession for their consideration.

That there is no absolute substitute for mother's milk no one will deny. That it is a vital fluid containing living protoplasm directly conveyed without possible contamination by air, dust, or germs from mother to child, and that no artificial substitute such as cow's milk more or less contaminated can possibly take its place, should also be generally accepted. The mother's milk is, like the mother's blood, aseptic, and at the body temperature given direct to the child. To use such milk, therefore, after it has remained outwith the body for many hours, when it has become not only altered but dead, so to speak, and grossly contaminated, must produce harmful effect upon the child.

Nature's methods are acknowledged by all to be the best, and on the nearness to which one approaches nature in seeking for a remedy will success or failure depend. The cow is by nature, judged from a medical, and still more so from a bacteriological, standpoint, a very filthy animal. Its fæces are of semi-solid consistence, and in consequence its hind quarters, including the udder, are always more or less smeared with dung. Any attempt (however attentive a farmer may be) to keep these parts clean is foredoomed to failure. The floors of the byre are for the same reason never clean, the fæces in falling being splashed in all directions. I agree, arguing from the public health point of view, that there is no reason why the animal and its surroundings should not be kept scrupulously clean, but such highly desirable conditions would handicap the farmer in the extreme and are not to be expected. Even were one to conduct the whole business of a dairy farmer on calf lymph laboratory lines, each step being rigidly aseptic (apart altogether from the cost), with the object of supplying as far as possible an aseptic fluid, the long interval which elapses during transit before consumption would result in a fluid far removed from what was originally desired. The teats for the same reason are always contaminated in part of their length and to insure a pure supply the first portion of the milk drawn should be discarded. Although a few cows are occasionally kept in town byres, thus bringing their milk more closely to the seat of consumption (the town infant), the majority are housed in the country. It is also a wellestablished fact that cows do not improve in health in confined spaces such as exist in towns, as they are very susceptible to disease, and that the practice of keeping cows in town byres is not to be recommended.

A large percentage of milch cows also suffer from general tuberculosis, and even a larger proportion suffer from tuberculosis of the udder. I have seen an udder riddled in its whole extent with tuberculosis, and yet the milk of the animal to which this udder belonged for many months was supplied to the city. That cows with udders in the early stages of tuberculosis still unrecognised-and without the assistance of the bacteriologist this condition is extremely difficult of recognition-are furnishing many millions of tubercle bacilli in their milk for consumption daily in many of our large towns no one who has any knowledge of the matter will deny. The extent to which human infection may result thereby has not yet been definitely settled, but some recent work in this direction carried out by Professor von Dungern and Dr. Smidt ${ }^{1}$ is worthy of mention. The conclusions at which they al rived in experimenting on the relationship between human and bovine tubercle bacilli in anthropoid apes were that the gibbon is equally susceptible to infection with both types of bacilli, and owing to the near

1 Arheiten aus $d \mathrm{~cm}$ hitiserlichen Ge undheitsamte, Band xxiii Helt $2,1906$. relationship of this animal to man it seems probable that a similar susceptibility to both varieties of the tubercle bacillus may be attributed to man. There was, however, in their feeding experiments a difference in the anatomical distribution of the lesions to which they call attention. In both animals infected with bovine bacilli the small intestine showed tuberculous ulcers and the mesenterio glands were greatly enlarged and caseous, whereas in the two gibbons infected with human bacilli by feeding no tuberculous lesions could be found either in the intestine or in the mesenteric glands. In the latter animals the primary lesions were in the lungs, in the former the oldest lesions were obviously those present in the intestines and mesenteric glands.

The inference which I draw from this work is that bacilli of bovine origin seem to select the intestine and to set up generalised tuberculosis and would explain the great prevalence of this disease amongst children fed on tuberculous milk, and bacilli of human origin seem to select the lungs and to set up phthisis pulmonalis, supporting the view that this disease is solely of buman origin. In other words, the cow is responsible for the prevalence of general tuberculosis of children, and phthisis pulmonalis is derived from a pre-existing case of the same disease in man. The number of their experiments, however, is not large enough, they state, to justify any confident expression of opinion on the subject.

In recent years the municipal milk depôt has occupied a prominent place in the prevention of infantile mortality, and although in Britain it is still in its infancy it has been in operation in France and elsewhere for many years. The function of the depôt is to supply sterilised milk, and although it is the desire to obtain that milk in the first instance as pure as possible, such is far from being the case. The gross amount of contamination of this milk, as of al other milk supplied to towns, is indicated by the fact that its bacterial flora is frequently much in excess of that of crude sewage or the washings of flock bed. The subject of flock beds has occasioned considerable excitement recently on account of the large amount of filth which they contain. Desirable as improved measures in this direction may be, they fall into insignificance compared with the greater dangers attending the actual consumption of similar filth and in greater amount as is usually contained in milk. To kermit milk to become grossly contaminated in the first instance and then to purify it by sterilisation not only falls far short of an approach to nature's own methods but alters its condition from that of a vital to a dead and less inferior nutritive article.

I have mentioned the chief objections to the cow as a source of milk supply and I purpose now contrasting those with the goat, feeling convinced that this animal will more closely meet the requirements. The goat is naturally a very cleanly animal. Its fæces are practically solid and rolled in balls so as to prevent any possibility of adhering to its hind quarters, and on this account those parts, as also the udder, are always fresh and clean. They dislike filthy surroundings and will not lie down amongst their excreta nor eat soiled fodder. This is an acknowledged fact by all who know anything of the habits of this animal. The cleanly habits of the goat thus remove the possibility of the more gross contamination of its milk at the source of supply. Goats being small animals compared with the cow and possessing a hardy constitution, and being practically immune from tuberculosis, can be kept in pens within the city without detriment to their health, although it might be advisable to let them loose in the open once a year when they can live on any uncultivated land and clean it for cultivation in a very short time. Indeed, they are employed for this purpose in the United States of America. It is to be remembered, however, that they do not furnish so much milk when thus fed as when ordinary fodder forms their staple food. A large number could thus be penned in each ward of the city to which a milk depôt might be attached and their milk drawn as $r \in q u i r e d$. Sterilisation would not be necessary, and the infant would be brought as close to the goat as possible and a natural and vital fluid supplied.

The goat is practically immune to tuberculosis and with but few exceptions the only instances in which this animal has been found to be suffering from this disease are when they have been closely housed with tuberculous cows and have obtained their infection therefrom. Professor Nocard states that out of over 130,000 goats and kids that hare been brought to Paris for slaughter at the shambles of La Villette 